\title{
CHANGE OF INTEREST AS A FUNCTION OF SHIFT IN CURRICULAR ORIENTATION ${ }^{1}$
}

\author{
EDWARD S. BORDIN \\ University of Michigan \\ and \\ EARL H. WILSON \\ Montana State College
}

THIs study represents an attempt to test one of the deductions derived from a theory of vocational interest measurement which has been outlined by the senior author (I). Within the framework of the Strong Vocational Interest Blank, it has been suggested "In answering a vocational interest inventory an individual is expressing his acceptance of a particular view or concept of himself in terms of occupational stereotypes"' $(\mathrm{I}: \mathrm{p}$. 53). At the same time two corollaries are presented:

I. "The degree of clarity of an interest type will vary positively with the degree of acceptance of the occupational stereotype as self descriptive."

2. "The degree of clarity of an interest type will vary positively with the degree of knowledge of the true occupational stereotype" (I: p. 53).

Elsewhere in the same discussion it is made clear that it is assumed that the methods of development of a vocational interest inventory like the Strong VIB has tended to insure that

\footnotetext{
1 The data on which this paper is based were collected by the junior author and reported in a master's thesis (8). The senior author took major responsibility for the preparation of this paper.

${ }_{2}^{2}$ The use of the term "stereotype" requires further clarification. Social psychologists tend to use the term "social stereotype" to refer to a distorted perception of a socially defined group of persons, e.g., religious, national, or occupationally defined. This distorted perception is usually thought of as being shared by a number of persons. In the present context, the term "stereotype" is broadened to refer to the salient characteristics of a perception of a socially defined group of people, in this case an occupational group. This perception may be either distorted or accurate, which would make it a false or a true stereotype. The perception could be unique to one individual or shared by a large number of individuals, which would make it either an ideosyncratic or a social stereotype.
} 
the stereotypes inherent in the occupational scales are accurate representations of the feelings of men in those occupations.

This interpretation of the phenomena involved in inventoried vocational interest leads to certain predictions based on hypotheses about the conditions under which self-percepts develop and are modified. Since it has been hypothesized that in the vocational inventory, an acceptance of a particular occupation stereotype as self-descriptive is being expressed, the self-percepts of the individual must be assumed as crucial to the result of interest measurement. One of the presumed factors in the development and modification of self-percepts, particularly those which impinge upon vocational interests, is the effect of the individual's process of reality testing, so well described by Carter (2). This point of view assumes that the pressures toward rational behavior tend to mold the individual's selfpercepts in the direction of consistency with his experiences and achievements. If this be the case, then curricular experiences can be assumed to affect interest scores to the degree to which these experiences lead to changes in self-percepts. If an entering freshman, who has considered himself skillful in mathematics and is planning to become an engineer, experiences considerable difficulty in mathematics, this experience will probably lead to a less clear percept of himself as an engineer.

It should be noted that this expectation is contrary to Strong's conclusions. After reviewing the results of a number of studies on permanence of interests, he concludes, "Vocational interests found among college students and to a lesser degree among juniors and seniors in high school cannot be attributed to formal training or experience in those pursuits" ( $7:$ p. 380 ). The theoretical position on which the present study is based assumes that the data which emphasize the permanence of interests reflect the relative stability of occupational pattern with increasing age. This increasing stability with age is a function of the increasing amount of investment in the particular goal with time, and of the effect of increasing responsibilities on the individual's freedom to start anew the slow process of establishing himself in some new occupational endeavor. Another possible source for persistence of vocational interests is the basic personality structure. Most theories of 
personality assume that more central or core aspects of personality are more persistent and more resistive to change. To the extent that vocational interests reflect such central factors, persistence of interests could be expected. It is our view that vocational interests represent derivations of central personality factors sufficiently removed from the personality core to be much less resistive to change.

\section{Problem}

A test of the influence of curricular experiences upon vocational interests can be provided by comparing tested interests of students prior to and at the end of the first college year. It seems safe to assume that this is a period of intensive reality testing of occupational choices which depend upon college training. If change in curricular orientation between the start and end of the first year in college can be taken as evidence of the result of reality testing and other concomitant influences upon the individual's self-percept, then contending theoretical interpretations of interest test phenomena can be tested against the relations between changes in curricular orientations and changes in in terests.

\section{Procedure}

Two hundred and fifty-six men in the 1946 freshman class at Washington State College comprised the sample for this study. The Kuder Preference Record (Form $B B)^{3}$ had been administered to all entering students in this class during the "Freshman Week" program prior to the beginning of the school year. The testing was part of the general procedures involved in curricular counseling with new students. Students were told that the test results would be useful in helping them choose a college curriculum or in checking on their chosen one. In most cases the student's interest test scores were interpreted to him during the curricular planning session. There was no particular pressure

\footnotetext{
${ }^{3}$ The use of the Kuder instead of the Strong raises questions as to how interchangeable they are. Some have suggested that the Kuder is more amenable to conscious manipulation than the Strong. However, study of manipulability of the Strong ( $\mathrm{I}$ ) suggests that both tests are susceptible to conscious manipulation. Longstaff (5) has presented the only objective evidence on this question and concludes that the Strong can be more readily faked upward and the Kuder more readily faked downward.
} 
for the student to make a curricular choice, since the college regulations did not permit an official curricular designation before the end of the first year. However, the curricular planning interviews at the time of the first testing included questions about his proposed curriculum with provision for recording of this information in the summary of the interview.

In the spring (April) of the same school year, the sample for retesting was obtained on a volunteer basis. The subjects were told that as a return for their participation in the study, the test results would be interpreted to them. Again, it was suggested that the test results would be useful as a check upon curricular choices. At no point was there any effort to imply that it was possible or desirable to make a special effort to have test results coincide with curricular choice. A structured interview provided information about the subjects' current curricular choices and their certainty of these choices as well as their recall about their certainty of their choices expressed at the start of the school year.

On the basis of profession of curricular choice at the start of the year, Kuder test profile at the start of the year, and curricular profession at retesting time, the subjects were divided and subdivided into the following groups:

I. Initial test profile was consistent with initial curricular choice.

(a) Followed curriculum plans consistent with their tested interests during the test retest period.

(b) Changed to a curriculum plan not consistent with tested interests.

(c) Changed to some other curriculum still consistent with tested interests.

2. Initial test profile and initial choice were inconsistent with each other.

(a) During intervening period changed to curricular choice which was consistent with initial test profile.

(b) Continued with initial curricular plan.

(c) Changed to a curricular plan, but one still inconsistent with initial test profile.

In order to define consistency or inconsistency between curricular choice and test profile, it was necessary to specify the 
TABLE I

Curriculum Profile Patterns

\begin{tabular}{|c|c|c|c|c|c|c|c|c|c|}
\hline Curriculum Pattern & Mec & Com & Sci & Per & Art & Lit & Mus & Soc & Cle \\
\hline 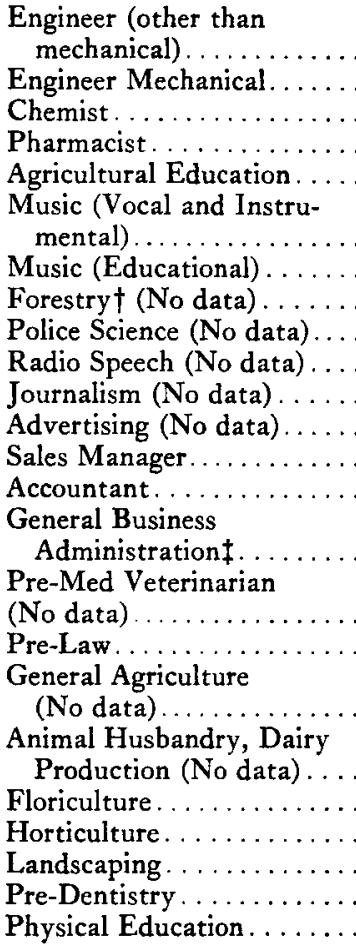 & $\begin{array}{l}9^{* * *} \\
94^{* *} \\
84\end{array}$ & $\begin{array}{l}50^{* *} \\
\mathrm{x}\end{array}$ & $\begin{array}{l}80^{* *} \\
73^{* *} \\
86^{* *} \\
72^{* *} \\
68^{*}\end{array}$ & $\begin{array}{l}x \\
x \\
x\end{array}$ & $\mathbf{x}$ & $\begin{array}{l}54^{* *} \\
5^{8^{* *}} \\
\\
\mathrm{x} \\
\mathrm{x} \\
\mathrm{x} \\
5 \mathrm{I}^{*} \\
53^{* *} \\
\mathrm{x}\end{array}$ & $\begin{array}{l}39^{* *} \\
40^{* *}\end{array}$ & $\begin{array}{l}78^{*} \\
79^{*} \\
80^{*} \\
\mathbf{x} \\
\mathrm{x} \\
\mathrm{x}\end{array}$ & $\begin{array}{l}61^{* *} \\
x\end{array}$ \\
\hline
\end{tabular}

* Positive differences significant at the 5 per cent level.

** Positive differences significant at the I per cent level.

$\dagger$ Patterns defined by $(x)$, represent a scale score at or over the seventy-fifth percentile. Other numbers are in terms of raw scores.

$¥$ This pattern was defined as containing either scale 2,4 , or 9 at the seventy-fifth percentile, plus 6 or 8 as a second high point.

criteria for this classification. The criteria for consistency of test profile with curricular choice as presented in Table I were based upon the following sources:

I. Table I, Classification of Occupations According to Major Interests, in the Revised Manual for the Kuder Preference Record (6: pp. 5-8).

2. Table 2, Mean Scores and Standard Deviations of Men in various Occupational Groups, in the same manual (6: pp. IO-I3). 
3. The pooled judgment of the writers, where information from the above sources was not directly translatable.

Where no definite data for defining critical scores were available, Kuder's suggested seventy-fifth percentile point was adopted. ${ }^{4}$ In some instances where data suggested a lower critical point and were based on a small number of observations, but where common sense suggested that the scale was an important one, the seventy-fifth percentile point was substituted.

When the criteria specified in Table I were applied according to the classification scheme outlined above, the distribution of subjects into the six sub-groups is obtained as shown in Table 2. A check on the accuracy of classification by having an inde-

TABLE 2

Distributions among the Six Groups

\begin{tabular}{cccc}
\hline Groups & N & Groups & N \\
\hline I a & 138 & $2 \mathrm{a}$ & 16 \\
Ib & 16 & $2 \mathrm{~b}$ & 63 \\
Ic & II & $2 \mathrm{c}$ & 12 \\
\hline
\end{tabular}

pendent judge classify a sample of 63 profiles yielded 96 per cent agreement.

Now that the conditions have been specified we are ready to translate our theoretical framework into specific predictions. This framework includes the assumption that our subjects were under pressure to make their curricular choices consistent with reality. It further assumes that an interest test reflects our subjects' perceptions of themselves within a curricular-vocational framework. Still another assumption is that curricular experience offers students an opportunity to check the accuracy of the curricular-vocational perceptions of themselves reflected in interest tests. It follows that, when a student pursues a curriculum inconsistent with his interest test profile, his experiences should lead to either a change in his curricular plans or a change in his interest test scores. If he does not change his curricular profession to bring it into line with interest test

${ }^{4}$ Subsequent consideration leads us to the conclusion that the percentile equivalent to the proportion of the general population represented by a given occupational group would probably be a more accurate critical point. However, we did not feel that this would influence the results sufficiently to warrant reanalysis of the data. 
scores, then it is predicted that he will change his perceptions of himself and consequently his interest test scores in the direction of his curricular professions.

Translated into specific terms, we arrive at the prediction that groups Ia, Ic, and $2 a$ will exhibit greater stability (testretest correlation) of their interest scores than groups $I b, 2 b$, and $2 \mathrm{c}$. A second prediction is that in the less stable group, the direction of change of scores will be consistent with the direction of shift in curricular orientation.

\section{Results}

Since the numbers in the sub-groups of the stable and instable groups were small the predictions were tested in terms of pooled sub-groups. This gave us sets of two correlations to compare for the stable and instable groups based on $\mathrm{Ns}$ of I65 and 9I, respectively. The method for testing the significance of the difference between two correlations as outlined by Fisher (3: p. I 88) was followed to estimate the probability that the two correlations for each scale were drawn from the same population. The obtained correlations, the difference and the corresponding value for $t$ are presented in Table 3 . It can be seen that with only one exception, the social service scale, the differences were in the predicted direction. Three of the nine differences were beyond the 5 per cent level of probability, where both ends of the sampling distribution are used. Considering the fact that our prediction specifies the direction of the difference, a more exact evaluation of the probabilities, using only one tail of the distribution, would include three more differences as falling beyond this probability level. Thus our first prediction has been amply confirmed. ${ }^{5}$

To show that the changes in interest scores, reflected in lower

' After this paper was submitted for publication, one of the editors raised the question as to whether the differences in correlation could have occurred because the stable group was more heterogeneous than the unstable group. This is a very logical issue and we are grateful for being reminded of it. There was in fact a tendency for the stable group to present a slightly but consistently higher standard deviation. However, the effect of these differences, when tested by Kelley's formula (4: p. 225) was found to be so slight as to leave the picture unchanged. For example, when the effect of greater homogeneity is allowed for the test-retest correlation on the Scientific Scale for the low group shifts from .51 to .56 . The largest shift was found in the Persuasive scale which was from $.5^{8}$ to .65 . Four of the scales showed no change, two increased two points and one increased three. 
test-retest correlation for the unstable group, were related to the direction of the shift in curricular orientation it was necessary to take into account the specific curricular shifts involved. As was true of most students in the college, the aspirations of the unstable group centered around curricula leading to occupations which tapped either the scientific, mechanical or persuasive interest scales. Of the ninety-one curricular choices represented at the time of the first test, 74 involved the scientific scale, 60 could be classified as mechanical and 15 as persuasive. ${ }^{6}$ At the time of the second test, 67 could be classified as scientific,

\section{TABLE 3}

Comparison of Observed Kuder Preference Record Test-Retest Correlation for Two Groups Expected to Differ in This Correlation as a Function of Stability

Factors in Their Curricular Orientation

\begin{tabular}{|c|c|c|c|}
\hline Kuder Scale & $\begin{array}{l}\text { Expected High } \\
\text { Test-Retest } \Gamma\end{array}$ & $\begin{array}{l}\text { Expected Low } \\
\text { Test-Retest } \mathrm{I}\end{array}$ & $\mathbf{t}$ \\
\hline Mechanical.... & .86 & .78 & I. 86 \\
\hline Computational...... & $\cdots \cdot .72$ & .59 & I.74 \\
\hline Scientific $\ldots \ldots \ldots$ & $\ldots .78$ & $.5 \mathrm{I}$ & $3 \cdot 5^{* *}$ \\
\hline Persuasive..... & .76 & .58 & $2.67^{* *}$ \\
\hline Artistic..... & $\ldots .83$ & .70 & $2.33^{*}$ \\
\hline Literary. . & $\ldots \cdot 7^{2}$ & .58 & 1.86 \\
\hline Music . . . . . . & $\ldots .83$ & .77 & I. I 8 \\
\hline Social Service. & ... 68 & .72 & 0.62 \\
\hline Clerical...... & $\ldots .74$ & .64 & 1.40 \\
\hline
\end{tabular}

** Beyond the one per cent level.

* Beyond the five per cent level.

48 as mechanical and 27 as persuasive. These data reflect the trend, observed in most colleges, for students to concentrate their interests in the scientific and technical fields initially and to shift to business and promotional fields as an alternative.

Since most of the expected changes in interest scores would involve these three scales, the analysis was confined to the scientific, mechanical and pursuasive scores. On the basis of the first test, the student's curricular choice at the time of the first test and his curricular choice at the time of the second test, predictions were made as to whether each of the three scores on the second test would show an increase, decrease or

\footnotetext{
- Since a curricular choice can be represented by more than one interest scale, the numbers representing interest scales will exceed the number of curricular choices.
} 
no change. The reasoning applied in making these predictions was in accordance with the theory outlined in the preceding discussions. The basic assumption was that these students were normal people and therefore responsive to reality and the need to be self-consistent. For example, if a student had planned on mechanical engineering at the time of his first test and his first test reflected relatively high interests in the scientific and mechanical fields and less than average interests in the pursuasive area, but at the time of the second test he had decided to go into business advertising field, then it was predicted that his scientific and mechanical scores would decrease and his persuasive scores would increase on the second test. When the actual numerical changes for each of the three groups, predicted increase, decrease, or no change, were analyzed for each of the three scales, it was found that increases were obtained as predicted, and that the mean differences for the decrease and no change groups were either close to zero or negative. Analysis of variances for each of the three scales indicated highly significant differences for the Scientific and Pursuasive scales ( $F$ vales of 21.90 and 33.40 , respectively, for two degrees of freedom) and a moderately significant difference for the Mechanical scale (3.98).

The student's report on his certainty about his curricular plans did not exhibit a significant relationship to the stability of his interest.

\section{Discussion}

The results of this study provide unequivocal support for the assumption that inventoried vocational interests are dynamic phenomena reflecting changes in the individual's perceptions of himself. The next question is that of the degree to which the self-percepts obtained in interest testing reflect unconscious as well as conscious attitudes. This question can be rephrased by asking how deeply embedded in the personality these selfpercepts are. That we find they are responsive to conscious shifts in attitudes seems to argue that these interest patterns are determined to a significant degree by conscious attitude sets. It seems likely that the influence of unconscious attitudes and feelings will vary according to the person. Where uncon- 
scious feelings must be strongly repressed and where these feelings are associated with the self-percepts reflected in vocational interests, then vocational interests will be more fully controlled by unconscious factors, and less responsive to the effects of reality testing operations.

The demonstration that tested vocational interests can change in accord with shifts in curricular orientation, as well as the reverse, has definite implications for the counseling use of interest tests. Among counselors there has been a general tendency to assume that a student's vocational interest score was a fixed reality to which he must adjust. The finding that students who persist in a curricular choice in the face of adverse interest patterns will show definite modifications of their interest patterns in the direction of greater self-consistency should give pause to those counselors who are inclined to interpret interest tests as evidence that students should change their curricular orientation. From our evidence, one could argue just as readily that the student should change his interests to fit his curricular orientation. Our theoretical position suggests that discrepancies between tested interests and curricular orientation simply identify possible areas of motivational conflict rather than the directions to be taken for resolving the conflict.

\section{Summary}

This study was designed to test the hypothesis that vocational interests reflect changeable self-percepts in vocationalcurricular terms. Two hundred and fifty-six Washington State College first year men students comprised the sample in which this hypothesis was tested. Kuder Preference Records were administered at the beginning and end of the school year. Also available was evidence of each subject's curricular orientation at the beginning and end of the year.

There were two major findings:

I. There was a predictable relationship between stability or instability of the test-retest results on the basis of consistency factors between interest pattern and curricular orientation.

2. Within the unstable group, it was possible to predict to 
a significant degree the direction of change in the scales critical for the curricula involved in the shifts.

\section{REFERENCES}

I. Bordin, Edward S. "A Theory of Vocational Interests as Dynamic Phenomena." Educational and Psychological MeasureMENT, III (1943), 49-65.

2. Carter, H. D. "The Development of Vocational Attitudes." Fournal of Consulting Psychology, IV (1940), I 85-191.

3. Fisher, R. A. Statistical Methods for Research Workers. London: Oliver and Boyd, 1938.

4. Kelley, T. L. Statistical Method. New York: The MacMillan Co., 1923.

5. Longstaff, H. P. "Fakability of the Strong Interest Blank and the Kuder Preference Record". Fournal of Applied Psychology, XXXII (1948), 360-369.

6. Revised Manual for the Kuder Preference Record. Chicago: Science Research Associates, 1946.

7. Strong, E. K., Jr. Vocational Interests of Men and Women. Stanford University: Stanford University Press, 1945.

8. Wilson, Earl H. Stability of Interest Patterns as Reflected in the Kuder Preference Record. Master's thesis, State College of Washington, $194^{8}$. 